\title{
VIOLA MODERNA: CONSIDERAÇÕES SOBRE QUATRO VIOLEIROS CONTEMPORÂNEOS
}

\author{
MODERN VIOLA: CONSIDERATIONS ON FOUR \\ CONTEMPORARY VIOLEIROS \\ Pedro Pereira Cury \\ Universidade de São Paulo \\ pedropcury@yahoo.com.br
}

\section{Resumo}

Neste trabalho busco refletir sobre a estética da viola instrumental no Brasil nas últimas décadas. Essa reflexão parte da identificação de elementos que foram incorporados nesse universo, apontando para um processo acentuado de modernização pelo qual passa o instrumento desde entornos dos anos 1980. $\bigcirc$ trabalho edifica a fundação de uma linguagem renovada da viola sobre a obra de quatro violeiros compositores tidos como referência: Almir Sater, Tavinho Moura, Ivan Vilela e Heraldo do Monte. Abordo também algumas questões históricas uma vez que esse movimento recente de retomada da viola nos meios urbanos é também um processo importante da trajetória do instrumento desde sua chegada no Brasil, ainda no século XVI.

Palavras-chave: Viola caipira; viola contemporânea; música instrumental brasileira. 


\section{Abstract}

In this paper I bring some discussion on the aesthetics of the instrumental music made for viola caipira in Brazil during the last decades. This reflection is based on the identification of elements that have been incorporated in this universe, pointing to an accentuated process of modernization through which the instrument passes since around the 1980s. This work builds the foundation of a renewed viola language on the work of four composers/violeiros considered as references: Almir Sater, Tavinho Moura, Ivan Vilela and Heraldo do Monte. I also address some historical issues, since this recent movement of retaking the viola in urban environments is also an important process of the trajectory of the instrument since its arrival in Brazil, in the 16th century.

Keywords: Viola caipira; Contemporary viola; Brazilian instrumental music.

\section{Introdução}

Quando se fala em viola no Brasil, hoje, é quase certo que nosso imaginário seja impelido à imagem e sonoridade associadas ao seu arquétipo caipira. De fato, o universo caipira é aquele no qual a presença da viola no Brasil se tornou mais marcante e difundida. $\bigcirc$ instrumento, no entanto, assume formas particulares por todo o país, como a viola machete no samba-de-roda da Bahia; a viola-de-cocho no cururu matogrossense; a viola caiçara no litoral paulista e paranaense ou a viola de repente em diversas partes da região nordeste. $\bigcirc$ protagonismo da vertente caipira da viola se associa a alguns mecanismos históricos e sociais a serem comentados adiante nesse trabalho.

Olhando um pouco mais de perto percebemos que o percurso da viola se estende tanto por os séculos que antecedem sua vivência caipira quanto, a partir dos anos 1980, para além do estereótipo interiorano que boa parte do século XX the conferiu. A viola figurou tanto como ferramenta de catequização, ainda no século XVI, quanto como instrumento acompanhador de cantigas populares nas esferas citadinas bem antes que pudéssemos falar em uma "cultura caipira", ou na dicotomia entre a música urbana e a música rural no Brasil. 
Otrabalho presente aponta para esse processo de transformação marcante que a viola vive desde as últimas décadas do século XX através da música de quatro nomes que podem ser apontados como os pilares dessa viola renovada da qual falamos: o matogrossense Almir Sater; Tavinho Moura, mineiro da Zona da Mata; o sul-mineiro Ivan Vilela; e o pernambucano Heraldo do Monte. Como a viola percorreu um caminho extenso e cheio de meandros até chegar às mãos desses e de outros violeiros da atualidade traço também um breve histórico da nossa protagonista desde quando radicou-se por essas terras.

Na última seção deste trabalho, faço uma breve descrição do material musical utilizado em um disco de cada um desses violeiros com intenção de apontar algumas das inovações técnicas e de linguagem trazidas por eles ao repertório de viola instrumental sugeridas aqui.

Como forma de esclarecimento indispensável enfatizo que a opção pelo termo "viola moderna" que intitula esse trabalho traz consigo a urgência por uma delimitação clara. A busca por um termo que defina esse movimento mais recente da viola no Brasil não é algo trivial pois expressões como essa utilizada aqui podem ser bastante controversas. Quando se usa "moderno" ou "contemporâneo" aqui não se deseja associar de forma alguma a viola atual com os ideais estético-artísticos do movimento modernista ou com aqueles da música contemporânea, propriamente. O termo "moderno" no título é empregado com cunho coloquial, reproduzindo a maneira como um violeiro antigo, por exemplo, se dirigiria à música em questão.

\section{A VIOLA E O CAIPIRA}

Falar de viola é falar de muitas violas. Apesar da enorme variedade de termos usados para seu desígnio, viola caipira é provavelmente aquele mais correntemente empregado hoje pra se referir ao instrumento de cinco ordens de cordas da família das cordas dedilhadas que aportou em terras tupiniquins já nas primeiras décadas que se seguiram à chegada dos portugueses.

Com quase cinco centênios de historia no Brasil, a viola, no entanto, só "se tornou" caipira no século XX. Até a primeira metade do século XIX noticia-se a presença marcante da viola na capital do Império 
através de documentos alfandegários e relatos de viajantes sobre festejos, danças e cortejos. Em meados do século XVIII havia mesmo no Rio de Janeiro a rua das Violas, estada de fabricantes desse e de outros instrumentos'. O nome da rua indica, então, a popularidade do instrumento e de seus artífices no epicentro do que se poderia delimitar socialmente como polo urbano brasileiro do período histórico em questão.

Em 1869 a rua das Violas ganhou novo nome e passou a chamarse rua Teófilo Otoni. A viola, que até então protagonizava o acompanhamento tanto das modinhas e lundus quanto das folias do Divino e outras danças na cidade do Rio de Janeiro, parecia, nesse momento, não se incorporar à proposta da belle époque carioca. Vale ressaltar que até o primeiro quartel do século XIX a principal festa popular da capital era a festa do Divino, onde a viola era central no acompanhamento instrumental.

Marcia Taborda (2011) fala sobre uma perfeita assimilação do violão pela sociedade carioca a partir da segunda metade do século XIX. Ainda que esse fato social seja coincidente com o momento de "ruralização"da viola seria simplista falar que nesse ponto histórico o violão substitui a viola na música urbana do Brasil. Os valores da burguesia européia, nos quais a sociedade carioca emergente se espelhava, determinaram a decadência das folias do Divino e de outras representações e ritos populares na capital do Império. A viola como peça fundamental nessas manifestações foi também então afastada do ethos urbano. Podemos afirmar que o violão substitui de fato a viola somente no acompanhamento das modinhas e lundus, uma vez que esses gêneros urbanos seguiram em alta no século XIX fazendo uso principalmente do violão acompanhando a voz.

Se na cidade do Rio de Janeiro a ampliação do setor médio urbano gerava uma demanda social por hábitos renovados que afastava os ritos e divertimentos populares e aspirava fundamentalmente a maneira parisiense nos costumes isso configurava, no entanto, um fenômeno relativamente local já que no restante do território nacional a população vivia essencialmente sob costumes rurais.

I Em seu livro Violão e Identidade Nacional (201 I) a pesquisadora Marcia Taborda cita uma série de violeiros, ou construtores de viola, estabelecidos na rua das Violas. Essa relação foi recolhida pela autora no Almanak da Cidade do Rio de Janeiro - 1792/1794. 
No nordeste brasileiro os repentistas e cantadores desde muito se apoiam na viola para entoar seus versos; no samba-de-roda da Bahia a viola machete ainda hoje é o instrumento de cordas central no acompanhamento; no fandango caiçara a viola é indispensável ao lado da rabeca. Nesses universos, e em quase todas as práticas festivas ligadas ao catolicismo compreendidas na cultura caipira², a viola tem longo retrospecto e cadeira cativa até hoje. A variedade tipológica, a diversidade de faturas e a grande variedade de usos da viola por todo território nacional nos mostram como não se pode alegar estritamente pelo caráter técnico a derrocada da viola no Rio de Janeiro do século XIX.

A maior projeção de som, o uso de cordas simples, a uniformidade na forma de afinação e padrões de construção são alguns dos argumentos através dos quais a literatura se empenha em justificar o preterimento da viola frente o violão no cenário carioca oitocentista. Precisamos complementar tais hipóteses pois a grande profusão de afinações relatadas nas pesquisas recentes relacionadas a viola, por exemplo, atesta como a diversidade nesse sentido não foi empecilho para a continuidade de sua prática em muitos cantos do Brasil. Em muitas regiões viola e violão seguiram, ainda, coexistindo, especialmente no universo dos gêneros que compõem o que hoje denominamos de música caipira; o chamado casal ${ }^{3}$.

A antropóloga Elizabeth Travassos comenta como "os instrumentos são artefatos mediadores de relações sociais e percorrem ao longo do tempo carreiras simultaneamente musicais e sociais" (Travassos, 2006, p. 130). A autora ainda traz uma reflexão interessante sobre como viola e violão têm representatividades sociais que se contrapõem sob certo valor simbólico e como isso é determinante na posição de cada instrumento: "Por mais que pertençam à mesma família organológica, violão e viola sinalizam dois universos sociais e simbólicos diferentes: a sociedade tradicional brasileira, predominantemente holística, e a sociedade moderna regida pelo valor do individualismo." (Travassos, 2006, p. 120)

2 A área que abriga o que chamamos de cultura caipira coincide com a região povoada pelas bandeiras, ou seja, São Paulo, Sul de Minas e Triângulo Mineiro, Goiás, Mato Grosso do Sul, parte do Mato Grosso, parte do Tocantins e norte do Paraná. Segundo Ivan Vilela (2013) essa macro-região é denominada Paulistânia, termo esse criado e definido por Alfredo Éllis Jr..

$3 \bigcirc$ par viola e violão é popularmente chamado de casal na música caipira. 
O pesquisador e violeiro Ivan Vilela (2013) chama atenção para um outro fator histórico do início do século XIX que, aliado à modernização dos meios urbanos, cooperou para o declínio da viola e dos ritos populares nas grandes cidades. Foram essas as romanizações que buscavam purificar os rituais católicos imbuidos de ritos pagãos e superstições cultivados pela população leiga, o que chamou-se de 'religiosidade colonial' ou 'catolicismo barroco'4. As violas, rabecas e outros instrumentos característicos foram sendo compelidos para os interiores e zonas rurais juntamente com esses ritos de "catolicismo popular".

Ainda que no final do século XIX e início do século XX a cidade de São Paulo configurasse espaço urbano significativamente distinto daquele encontrado na cidade do Rio de Janeiro do mesmo período houve também processo parecido com relação ao deslocamento dos festejos e danças religiosas populares, e por conseguinte, da viola.

Se com a transferência da corte portuguesa, nas primeiras décadas do século XIX, para a cidade do Rio de Janeiro havia se importado também os valores e maneiras europeus, é somente nas décadas que antecedem o século XX que a cidade de São Paulo passa a perceber efeito de norma social semelhante. As oligarquias cafeeiras edificavam uma cidade próspera e modernizada, vislumbrava-se assim uma sociedade com hábitos refinados à maneira européia.

historiador Odilon Nogueira de Matos aponta para esse crescimento acentuado da cidade paulistana nas três últimas décadas oitocentistas quando sua população passa de 31 mil para 240 mil habitantes, de 1872 a 1900. Esse crescimento vigoroso pelo qual passava a cidade de São Paulo envolveu, no início do século XX um fluxo muito grande de migrantes das zona rurais para a cidade. Tão massivo foi esse movimento que com o tempo muitas dessas festividades foram revitalizadas na cidade.

Ivan Vilela discorre sobre esse movimento de migração da população rural para a cidade em São Paulo e ainda aponta para a presença de muitas Folias de Reis encontradas ainda hoje em centros urbanos da capital paulista e região metropolitana. $\bigcirc$ autor comenta também sobre fenômeno análogo na Baixada Fluminense e nos morros

4 Esses termos são levantados pela pesquisadora Martha Abreu em $\bigcirc$ Império do Divino (1999). 
da cidade do Rio de Janeiro "onde ainda persistem manifestações como as folias, os calangos e o jongo" (Vilela, 2013, p.64).

Houve ainda outro agente fundamental para a afirmação dos valores da cultura caipira, sobretudo da música caipira, no grande centro urbano da Pauliceia na primeira metade do século XX: o disco. Esse advento pode ser considerado um dos elos fundamentais entre a "viola camponesa" e a "viola moderna" tratadas nesse trabalho.

\section{A GRAVAÇÃO E A MÚSICA CAIPIRA}

Cornélio Pires, paulista de Tietê, promoveu em 1929 a gravação de uma série de 6 discos com duplas caipiras, causos, anedotas e desafios que tiveram enorme sucesso de vendas. Inicialmente foram produzidas 30 mil cópias dos discos lançados pela Columbia. A iniciativa de Cornélio teve consequências determinantes para o caipira, sua música e para a viola.

Primeiramente, as gravações fariam com que as danças e festividades rurais do caipira, como o cururu, cateretê, caninha-verde e a moda-de-viola, fossem registrados em forma de canção sendo daí em diante passiveis de registro fonográfico. É a partir dessa fase que a expressão 'música caipira' ganha a significação como a conhecemos hoje, como a música que vem do universo caipira.

Não é o objetivo desse trabalho discorrer especialmente sobre o desenvolvimento que a música caipira teve a partir da sua gravação, artisticamente ou sob ponto de vista midiático. É importante, no entanto, ressaltar que esse desenvolvimento fonográfico foi um agente fundamental na constituição de artistas ligados a essa música e também à viola.

\section{OS VIOLEIROS}

A dimensão do sucesso das duplas caipiras foi algo grandioso e reverbera até os dias de hoje em artistas de uma nova geração que 
fazem uso dessa formação vocal, mesmo que com uma música já muito transformada sob ponto de vista estético e conceitual em relação aos gêneros das primeiras gravações. Houve também, paralelamente e com projeção consideravelmente mais modesta, a promoção de instrumentistas ligados a esse universo, sobretudo violeiros.

Muitos destes violeiros desenvolveram trabalhos instrumentais, como Zé do Rancho, Bambico e Tião Carreiro, os três ligados à chamada música caipira ou sertaneja, sem, no entanto, caracterizarem um movimento destacado das modas cantadas ao acompanhamento da viola. Ainda no âmbito caipira, Gedeão da Viola deixou um legado precioso com composições que acabavam por expandir, neste universo, a maneira de se tocar o instrumento.

Se consideramos que todos esses violeiros citados pertencem a uma geração mais tradicional, de certa forma, e que existe, hoje, um movimento mais 'moderno', ou 'contemporâneo', ligado a viola então há um elo incontestável entre essas duas fases: o mineiro Renato Andrade.

Renato foi um dos primeiros a associar dois universos: a formação convencional da música de concerto com a música de tradição popular, sobretudo no âmbito caipira. Como o próprio Renato dizia, em sua obra conviviam 'o concertista e o capiaú. Através de uma formação clássica o ex-violinista introduziu elementos novos no universo da música de viola, especialmente com relação à técnica de mão direita. Se sob ponto de vista do desenvolvimento harmônico, em relação à música até então executada na viola, a música de Renato Andrade não logrou um avanço tão significativo como aquele que viria na geração seguinte, sua contribuição quanto às texturas e articulações foi grandiosa.

\section{A VIOLA SEMPRE EM ATUALIZAÇÃO}

Renato Andrade é referência para a grande maioria de violeiros das gerações que o sucederam. Entre esses herdeiros de Renato estão os quatro nomes citados anteriormente nesse trabalho. Percebemos essa influência tanto no desenvolvimento técnico quanto no próprio discurso desses violeiros que afirmam ter em Renato uma grande referência. 
A opção por falar da viola em seu estado atual através desses quatro violeiros se dá principalmente pelo seu protagonismo indiscutível no cenário relacionado à viola assim como pelo pioneirismo de seu trabalhos, por meio de alguns parâmetros estético-musicais a serem levantados adiante.

Existe, ao mesmo tempo, uma questão de diversidade geográficacultural relativa à origem e vivência desses compositores. Almir, enquanto violeiro, está ligado principalmente à tradição de viola do Mato Grosso e da região de fronteira; Tavinho é nascido em Juiz de Fora e traz no seu estilo uma autenticidade que não se pode associar facilmente a uma determinada tradição, no entanto, tem uma vivência musical no norte de Minas Gerais que aproxima sua música da cultura dessa região; Ivan é de Itajubá e está fortemente ligado à cultura caipira do sul de Minas e interior de São Paulo e traz uma influência diversa para perto dessa música; por fim, o pernambucano Heraldo, um ícone para a difusão de uma linguagem nordestina para viola, ainda que seja conhecido maioritariamente como guitarrista.

Almir Sater se associa fortemente à viola como músico e compositor mesmo que em sua extensa discografia, mais de 15 discos, como compositor e intérprete muitas vezes se apresente como violonista e cantor. Almir gravou Instrumental, em 1985, e Instrumental II, em 1995, seus dois trabalhos dedicados exclusivamente à viola instrumental.

Caboclo d'Àgua é o primeiro de três discos nos quais o "sócio" da turma mineira do Clube da Esquina Tavinho Moura toca exclusivamente viola. Em 1995 lançou Diadorado e em 2015, Beira de Linha, ambos de viola instrumental. No trabalho mais recente Tavinho toca sozinho em 11 das 13 faixas, o que diferencia esse trabalho dos anteriores nos quais quase sempre havia acompanhamento de outros instrumentos nos arranjos. Tavinho tem outros 14 discos seus gravados atuando como compositor, cantor, violonista e violeiro.

Dentre os violeiros citados Ivan Vilela é aquele que tem a obra mais extensa voltada para o instrumento tendo lançado mais de 10 discos como violeiro, tocando viola solista e também como acompanhador. Formado em Composição pela Unicamp e tendo iniciado a carreira como violonista, Ivan é um entusiasta da cultura caipira, mas não deixa de expressar a pluralidade musical de sua formação e de um universo atualizado nas suas gravações e composições pra viola. Gravou

\section{6}

REV. TULHA, RIBEIRÃO PRETO, v. 2, n. 2, p. 8-28, jul.-dez. 2016 
Beatles e Tião Carreiro além de criar a música de uma ópera caipira, Cheiro de Mato e de Chão, com libreto do poeta Jehovah Amaral, e executá-la com uma "orquestra caipira" idealizada por ele, no final dos anos 90. As inovações da viola de Ivan passam por conduções de vozes cuidadosamente construídas e soluções de harmonia pouco usuais à música tradicional além de uma técnica de mão direita expandida na qual as dez cordas passam a ser tocadas de forma independente.

Se os violeiros supracitados todos tem alguma ligação com o violão, o representante nordestino da viola nesse trabalho, Heraldo do Monte, tem uma longa carreira prioritariamente reconhecido como guitarrista. No entanto, a viola permeia o trabalho do pernambucano desde o início da carreira e já nos anos 60 Heraldo introduzia o instrumento em formações pouco usuais para a viola na época, como no grupo Quarteto Novo. Além de Viola Nordestina Heraldo gravou o MPBaby Moda de Viola, em 2004, e lança em 2016 o disco Heraldo do Monte, no qual apresenta choros seus através da viola acompanhada de seu regional ${ }^{5}$.

\section{OS DISCOS}

Nessa seção do trabalho faço uma pequena resenha de um disco de cada um dos quatro violeiros citados que vejo como de influência marcante para a viola instrumental. Instrumental, de Almir Sater, lançado em 1985; Caboclo D’Água, de Tavinho Moura, em 1992; Paisagens, de Ivan Vilela, em 1998; e Viola Nordestina, de Heraldo do Monte, em 2001.

5 Eduardo de Lima Visconti escreveu na sua dissertação "A Guitarra Brasileira de Heraldo do Monte" (2005) com foco nas composições e improvisos de Heraldo. Nessa pesquisa - autor expõe uma série de análises de trechos de gravações e entrevistas completas com o próprio músico.

\section{7}




\section{Instrumental I}

Em seu primeiro trabalho instrumental, Almir Sater deixa evidente a pluralidade de suas influências e incorpora elementos pouco usuais no universo ligado à música tradicional como bateria eletrônica, cítara e berimbau no acompanhamento de gêneros como o cururu, o chamamé e o arrasta-pé. As soluções harmônicas empregados também mostram a convivência entre uma linguagem mais atual e aquela tradicionalmente empregada sintetizados nas composições e arranjos. Ao longo do disco Almir usa diferentes afinações como rio-abaixo (em sol), naturap e cebolão (em mi). Nesse disco alguns nomes conhecidos como Tavinho Moura, Alzira Espíndola, Papete, Zé Gomes, André Gomes, Capenga, Carlão de Souza e Guilherme Rondon, acompanham Almir.

A primeira faixa do disco, Corumbá, é um chamamé lento, executado com viola e violão. Almir desenha melodias bem definidas ritmicamente usando escalas duetadas com acompanhamento marcado pelo violão durante toda a faixa. As escalas duetadas são um recurso muito característico da música caipira e da linguagem tradicional de viola ligada a esse universo. Almir faz uso desse tipo de recurso melódico em praticamente todas as faixas do disco.

Bem apoiada na tonalidade de sol maior, há dois elementos que saltam aos ouvidos nessa composição. A melodia inicial parte de um acorde de tônica e vai para a dominante, e logo na sequência há um acorde de segundo grau menor com sétima, onde a melodia se apoia no sétimo grau do mesmo acorde. Essa ocorrência melódico-harmônica acontece diversas vezes nesta música e pode ser reconhecida em muitas outras de Almir, trazendo uma sonoridade que pode ser associada a estruturas harmônicas de gêneros da música pop.

Mais adiante, a melodia se apoia numa sétima maior do acorde de tônica durante quase dois compassos completos, o que volta a acontecer conforme a forma da música se repete. Esse tipo de tensão é, também, algo pouco usual no repertório tradicional. Almir usa a melodia sobre a sétima maior do acorde em outras faixas. Ainda nessa mesma faixa Almir faz uso de bends na melodia, recurso próprio dos guitarristas

6 Em algumas faixas, em Doma por exemplo, Almir usa a quinta corda afinada em sol e não em lá como é mais comumente encontrada na afinação natural. 
para chegar-se a uma nota meio tom acima escorregando o dedo que prende a corda na mesma casa.

Em Luzeiro, a quarta faixa do disco, Almir combina a bateria eletrônica e o berimbau com a viola e percussão. Com exceção da viola, que pode ser ouvida durante o tempo todo, esses outros elementos entram e saem muitas vezes no decorrer da música. Nessa música ouvimos um recurso que se tornou característico desse violeiro: um ostinato rítmico da mão direita, enquanto a melodia caminha no dedilhado da mão esquerda, sempre acompanhada do bordão repetido. Em Doma, o compositor também usa esse ostinato da mão direita. Outro recurso que aparece aqui e que se repete na obra de Almir são as melodias que ora caminham sobre os tempos fortes ora são deslocadas.

Com relação a harmonia, há uma introdução com acordes suspensos (sus), sem terças, seguidos de um acorde com terça maior e menor juntas na mesma oitava, formando uma segunda menor. Esse último pode ser interpretado como um acorde maior com nona aumentada.

A melodia que segue após a introdução está no modo de Si mixolídio, ou seja, tem o sétimo grau rebaixado. A utilização desse modo é comum na música nordestina e no norte de Minas mas não é usual na música caipira, no entanto, o violeiro Tião Carreiro já fazia uso desse modo nos seus pagodes de viola. Almir utiliza esse modo também em outras músicas do disco e tem uma influência perceptível de Tião Carreiro na forma de tocar e compor.

Almir gravou somente duas músicas de autoria de outros compositores. A primeira delas é a conhecida Rio das Lagrimas, parceria de Tião Carreiro, Lourival dos Santos e Piraci. A versão de Almir ganhou uma melodia consideravelmente retocada e harmonia também re-elaborada onde se combinam um acompanhamento com baixo melódico do violão, em modo mixolídio, com arpejos com cordas soltas na viola. Além das adaptações melódicas o violeiro ainda transforma o modo jônio da melodia original em mixolídio.

A segunda faixa não autoral do disco é Na Piratiniga: de Jeep, de Tavinho Moura, que gravou o violão cuidadosamente arranjado com a viola de Almir. A forma de viola e violão caminharem no arranjo é consideravelmente distinta das demais faixas do disco. $\bigcirc$ violão faz melodias em uníssono e em aberturas de vozes com a viola de tal forma

\section{9}

REV. TULHA, RIBEIRÃO PRETO, v. 2, n. 2, p. 8-28, jul.-dez. 2016 
que não fica delimitado, como nas demais faixas do disco, qual instrumento é solista ou acompanhador. Essa forma de diálogo entre esses dois instrumentos é característico do trabalho de Tavinho.

Ainda nessa música, pode-se ouvir duas partes com formas de compassos distintas. Um primeiro momento marcado em divisão ternária que depois passa para binária $e$, finalmente, volta a parte inicial, como uma estrutura formal em A-B-A.

Em Doma, umas das composições instrumentais mais conhecidas de Almir?, encontramos vários elementos já levantados aqui. $\bigcirc$ ostinato rítmico no dedilhado arpejado da mão direita, ao uso do modo mixolídio assim como o deslocamento do tempo forte na melodia inicial e a melodia apoiada na sétima maior do acorde maior de função tônica. Nessa versão Almir usa viola e rabeca que se entrelaçam sem prioridade de acompanhamento ou solo.

Na última faixa no disco, ...É de Minas pra Riba, Almir combina viola, rabeca e citara. A faixa tem uma harmonia estática em um acorde em quase toda a música e melodia que se repete na viola, comentada pela rabeca e citara de forma improvisada.

\section{Caboclo d’Água}

Quem ouve esse primeiro trabalho de Tavinho com a viola protagonista certamente é remetido a uma atmosfera interiorana, de mato e campo. Tavinho traz, ao longo do disco, uma sonoridade que alia os motivos da música de tradição rural do norte mineiro com um desdobramento de arranjos meticulosamente construidos. Todas as faixas são composições do mineiro ou parcerias exceto Inhuma, de Zezinho da Viola.

A sonoridade combinada entre viola e violão é o ponto de partida neste trabalho de Tavinho, ainda que o autor faça uso de formações maiores em algumas faixas do disco. $\bigcirc$ também mineiro Beto Lopes é o responsável pela execução do violão em mais da metade das faixas do disco e são deles os arranjos de violão nas faixas em que toca.

7 Almir Sater divide a autoria e execução dessa música no disco com o violinista Zé Gomes. 
É interessante ressaltar que o casal - violão e viola - é a formação mais usual na música instrumental para viola no universo dos violeiros tradicionais. Ao mesmo tempo que Tavinho se apoia fortemente nessa configuração instrumental a sonoridade impressa ali está severamente remodelada. Existe uma ideia de unidade muito forte entre os dois instrumentos que executam, em muitos momentos, melodias em uníssono e ainda se aproximam timbristicamente pelo toque da viola sem o uso das unhas.

Assim como Almir, Tavinho também explora as escalas duetadas em praticamente todas as faixas do disco. Há também passagens, como em Mato Grosso, onde o compositor parte de uma desenvolvimento harmônico simples mas expande a sonoridade através de um acompanhamento com acordes carregados de tensões pouco usuais na música de tradição rural. Ainda em Mato Grosso, Tavinho inicia a música no acorde maior de função tônica e logo deixa soar um intervalo de sétima maior na viola. Em seguida surge um acorde de tônica menor com sexta. Esse acorde pode ser interpretado como um quarto grau com sétima, ou quarto blues, como é na tratado pela harmonia funcional.

disco traz uma série de composições que transitam entre tonalidades menores e maiores, como em Caboclo d'Água, Manoelzim da Crôa, Encontro das Águas, Minas Texas e Coração Disparado. Essa incorporação dos modos menores acontece com pouca frequência nas modas instrumentais para viola tradicionalmente.

Em Encontro das Águas, Tavinho opta por acompanhar a viola com piano e violões além de um teclado com timbre de cordas. Nessa faixa os violões foram gravados por Gilvan de Oliveira e Nonato Luiz. Outra faixa com instrumentação inusitada é Minas Texas, na qual Tavinho toca violão na primeira parte e volta à viola na segunda. $\mathrm{Na}$ primeira parte da música o autor remete à música norte-americana dos antigos filmes de 'bang-bang' fazendo uso de banjo e violino no corpo instrumental. Na segunda parte, Tavinho expõe um tema de sonoridade mais rural, alusivo à música tradicional mineira, completando a associação Minas - Texas. Essa música fez parte do filme brasileiro homônimo, no qual Tavinho participa atuando ${ }^{8}$.

8 Minas Texas é um filme brasileiro de 1989, com direção e roteiro de Carlos Alberto Prates Correia. 
Percebe-se, ao longo desse disco, um recurso técnico bastante recorrente na execução de Tavinho que é o toque repetido na mesma corda, da mesma nota, com indicador e dedo médio da mão direita alternadamente enquanto a melodia é executada pelo polegar. Em Manoelzim da Crôa, por exemplo, há algumas passagens nas quais o violeiro usa essa técnica. A técnica de mão direita de Tavinho é bastante singular e utiliza somente o polegar, indicador e dedo médio.

Observa-se também o uso de fórmulas de compassos variáveis em algumas músicas. Manoelzim da Crôa também pode exemplificar esse recurso composicional de Tavinho. $O$ deslocamento de tempo da melodia é feito com sutileza de forma que não há uma quebra de fluidez nas passagens onde as fórmulas se alteram. Tavinho afina sua viola em rio-abaixo (em sol maior) com a quinta corda afinada na nota sol.

\section{Paisagens}

Ivan Vilela é o mais jovem dos violeiros aqui tratados $e$, no entanto, é aquele com a discografia mais extensa voltada para a viola. Paisagens conta com a participação dos músicos Ricardo Matsuda, Luiz Henrique Fiaminghi, Roberto Magrão Peres, Mané Silveira e João Carlos Dalgalarrondo, mas grande parte do disco está centrado nas composições e arranjos cuidadosamente executas na viola.

Há um grande cuidado na construção do equilibrio de timbres dos instrumentos em todo o disco. Ivan usa o toque nas cordas com unha e a polpa do dedo combinados conferindo à viola um timbre aveludado e com grande controle de harmônicos. Dentre os discos aqui tratados este trabalho é aquele no qual mais claramente pode-se perceber uma influência da música de câmara. Há uma alusão à tradição rural da viola que permeia todo o disco, ora de forma mais direta como em Cururu pra São João, Catira de Mariamar ou No Balanço do Jacá - , ora velada em cenários sonoros, como proposto em Paisagens ou Calma Roceira.

Outra característica marcante desse trabalho são harmonias que se estendem através de longos acordes, ou passagens de acordes. Um exemplo dessas harmonias responsáveis por paisagem sonora intensa no disco é A Força do Boi, na qual há um desenvolvimento harmônico 
elaborado com empréstimos modais e acordes cheio de tensões e, ao mesmo tempo, há um pedal na nota tônica (ré) que se mantém durante praticamente toda a música. Essa forma de construção harmônica, através de condução meticulosa de vozes, é algo marcante no trabalho de Ivan, de uma forma geral, tanto nas composições e arranjos para viola solo quanto na viola como acompanhamento.

Assim como é comum à técnica de alguns violeiros mais antigos, Ivan usa também os harmônicos em construções melódicas. Isso acontece na introdução de Pra Matar a Saudade de Minas, Nananenem, Paisagens e Solidão. A forma como essa técnica é utilizada, usando indicador apoiando a corda e o dedo médio pinçando a corda, deriva da técnica violonística e permite que se possa executar harmônicos em praticamente todas as alturas.

Uma das extensões técnicas iniciadas por Ivan é a possibilidade de uso das dez cordas de forma independente. Pode-se ouvir esse uso na introdução de Armorial, onde só é tocada a corda ré aguda do quarto par enquanto a melodia é executada no primeiro e segundo par. Nessa mesma musica há também um ostinato melódico enquanto o baixo da viola faz um caminho melódico nos pares graves. Em Armorial, Ivan usa o modo mixolidio em uma referência à sonoridade nordestina já que a música é uma homenagem ao Movimento Armorial, idealizado em Recife nos anos 1960.

As duas músicas do disco que não são composições de lvan ganharam versões com teor estético consideravelmente distinto. Em Saudade da Minha Terra, de Coiá e Belmonte, o arranjo com violão e rabeca não pretende se afastar muito da estética tradicional dessa guarânia, apesar de algumas soluções harmônicas particulares do arranjo. Já na célebre Asa Brasa, de Luiz Conzaga e Humberto Teixeira, o arranjo para viola solo apresenta re-harmonizações e alterações melódicas, além de interlúdios com melodias próprias da versão. O Baiãozim Calungo é a outra musica do disco que faz referência ao nordeste, além de Asa Branca, Armorial e A Força do Boi. 


\section{Viola Nordestina}

Heraldo do Monte, como único representante nordestino entre os quatro violeiros abordados nesse trabalho, se distingue também pelo fato de ter se voltado para a viola após uma formação fundamentalmente construída através da guitarra, e não do violão. Heraldo faz soar na viola sonoridade de timbre notadamente distinta dos três demais pelo fato de pinçar as cordas com palheta?. Por conseguinte, sua forma de tocar viola é mais melódica, assim como a dos violeiros repentistas do nordeste brasileiro.

Neste disco Heraldo gravou músicas próprias e de outros compositores, todos nordestinos, sempre usando sua viola de 12 cordas. Como o próprio Heraldo comenta, a sua opção tanto pela viola de 12 cordas, e não 10, quanto pela afinação natural - ou seja, idêntica à do violão - se justifica pela facilidade de execução que isso the proporciona, por conta de sua pratica enquanto guitarrista. Heraldo coloca, ainda, que no nordeste não existe a mesma padronização na variedade de afinações e que cada violeiro afina da forma que the convém ${ }^{10}$.

O disco inteiro é feito somente com instrumentos de cordas dedilhadas e percussão. A sonoridade, portanto, está direcionada para uma reprodução do som acústico. Nas faixas Darlene Triste, Maria Bethania e Estrela Maga dos Ciganos, Heraldo opta pelo casamento antigo entre violão e viola. $\bigcirc$ violão que faz esse acompanhamento tem, aqui, cordas de aço dando sonoridade particular ao duo, evidenciando um timbre mais apoiado nas frequências médias e na abundância de harmônicos.

Há nesse trabalho de Heraldo uma estética voltada para melodias simples e modais, características correntes da música de viola no nordeste. Em faixas como Rapadura, Roseira do Norte, Viola Nordestina, Cabocolinho e Janga as melodias são construidas sobre o modo mixolídio com o quarto grau aumentado, modo muito usual na música

\footnotetext{
9 Ivan Vilela comenta que como consequência das instâncias administrativas portuguesas estarem mais voltadas para o nordeste durante muitos anos durante o período colonial, por conta da cana-de-açúcar, algumas maneiras cultas se firmaram também na forma de tocar. $\bigcirc$ uso da palheta e a forma mais melódica do que harmônica de se tocar foram algumas dessas heranças (2013).

10 Essa afirmação colabora com a hipótese de que o processo de gravação da música caipira, promovido por Cornélio Pires, foi determinante para a delimitação dos toques e das afinações da viola caipira. =
}

\section{4}

REV. TULHA, RIBEIRÃO PRETO, v. 2, n. 2, p. 8-28, jul.-dez. 2016 
nordestina. Quando há uma tendência modal em tonalidades menores, o modo dórico é o mais frequente, como em trechos de Viola Nordestina e Lágrima Nordestina.

Mesmo usando a palheta há muitos momentos no disco em que Heraldo realiza acordes e melodia, simultaneamente, na viola. A faixa que dá nome ao disco é toda tocada dessa forma e varia entre melodia acompanhada por uma nota tônica pedal e melodias construídas só com acordes. Nessa música aparece o quarto grau aumentado também em modo dórico.

Heraldo explora uma variedade de ritmos nordestinos no acompanhamento, como o maracatu em Janga ou a ciranda em Primeiro Sorriso. Na versão da valsa-choro Maria Bethânia, de Capiba, Heraldo mostra como enxerga a viola como instrumento apto ao universo do choro. Essa intenção se concretizou recentemente em forma de disco em Heraldo do Monte, lançado em 2016 e composto por choros autorais tocados na viola. 


\section{CONCLUSÃO}

A grande profusão de recursos musicais, que podem ser tomados como inovadores, notados nos trabalhos desses músicos aqui citados mostra como existe um processo sólido de contínuo caminhar ligado à música de viola no Brasil. Essa continuidade se dá desde a chegada do instrumento nesse continente e se a imagem que se estabeleceu como dominante é aquela associada a uma linguagem essencialmente caipira, existe, no entanto, um lastro enorme tanto para o passado quanto para o estado presente da viola que ainda carece de um olhar mais próximo.

O fato da viola ter sido, a partir de determinado momento histórico, tomada nos braços da população fundamentalmente camponesa em muitas regiões do Brasil fez, fortuitamente, com que não houvesse uma padronização tanto com relação à sua construção quanto com relação à forma de se tocar o instrumento. O material tratado na última seção desse trabalho confirma essa multiplicidade associada ao instrumento em questão e como há uma estrada aberta para um vasto campo de possibilidades de sonoridade e uso em geral da viola.

Esse movimento de retomada da viola na cidade parte também do desejo de alguns de trazerem um pouco do campo para os grandes centros, 'ruralizando' a forma de se viver ali. Os valores de solidariedade, comunhão e a ligação com a natureza são carregados pela viola e pela música. A viola é, mais uma vez, um agente simbólico de enraizamento e mediação em um tempo de transformações aceleradas no mundo atual.

\section{REFERÊNCIAS BIBLIOGRÁFICAS}

ANDRADE, Mário de. Dicionário Musical Brasileiro. São Paulo, EDUSP, 1989.

ARAúJO, Mozart de. A modinha e o lundu no século XVIII. São Paulo, Ricordi Brasileira, 1963.

CORRÊA, Roberto. A arte de pontear viola. 2a ed. Brasilia, Viola Corrêa, 2002. 
FERRETE, J.L. Capitão Furtado: viola caipira ou sertaneja? Rio de Janeiro, FUNARTE, 1985.

LIMA, Cássio Nobre de Souza. A viola nos sambas do Recôncavo Baiano. Dissertação de mestrado. UFBA, 2008.

MATOS, Odilon Nogueira de. A cidade de São Paulo no século XIX. São Paulo, Revista de História da USP, v. 10, n. 21 -22, 1955.

MORAIS, Manuel. A viola da mão em Portugal. Zaragoza, Revista Aragonesa de Musicologia XXII, 2006.

NEPOMUCENO, Rosa. Música Caipira: da roça ao rodeio. São Paulo, Editora 34, 1999.

OLIVEIRA, Allan de Paula. O tronco da roseira: uma antropologia da viola caipira. 2004. Dissertação de mestrado, UFSC.

Miguilim foi pra cidade ser cantor: uma antropologia da música sertaneja. 2009. Tese de doutorado, UFSC.

PEREIRA, Vinícius Muniz. Entre o Sertão e a Sala de Concerto: Um Estudo da Obra de Renato Andrade. 2011. Dissertarão de Mestrado, Unicamp.

SANDRONI, Carlos. Samba de roda, patrimônio imaterial da humanidade. Estudos avançados vol.24, no.69, p.373-388, 2010.

Feitiço decente: transformações do samba no Rio de Janeiro (1917-1933). Rio de Janeiro, Jorge Zahar, Ed. UFRJ, 2001.

SARDINHA, José Alberto. Tradições Musicais da Estremadura. Lisboa, Ed. Tradisom, 2000.

TABORDA, Márcia. A viola de arame: origem e introdução no Brasil. Revista Em Pauta, v. 13, n. 21, dezembro 2002.

Violão e Identidade Nacional. Rio de Janeiro. Editora Civilização Brasileira, 2011. 
TINHORÃO, José Ramos. Historia Social da Música Popular Brasileira. São Paulo, Editora 34, 1998.

Paulo, Art. Editora, 1991.

Pequena história da música popular. São

TRAVASSOS, Elizabeth. O destino dos artefatos musicais de origem ibérica e a modernização no Rio de Janeiro (ou como a viola se tornou caipira). In: VELHO, Gilberto; SANTOS, Gilda. (org), 2006. Artificios e artefactos: entre o literário e o antropológico. Rio de Janeiro, Ed. 7 Letras, 2006.

VEIGA de OLIVEIRA, Ernesto Veiga de. Instrumentos musicais populares portugueses. Lisboa: Fundação Calouste Culbenkian / Museu Nacional de Etnologia, [ 1964] 2000.

VILELA, Ivan. Cantando a própria história. Artigo na Revista de Cultura Artística de Piracicaba, n 3, 2009.

Vem viola, vem cantando. Estudos avançados. USP, 2010

Cantando a Própria História: Música Caipira e Enraizamento. Editora da USP. 2013.

VISCONTI, Eduardo de Lima. A Guitarra Brasileira de Heraldo do Monte. Dissertação de Mestrado. 2005, Campinas, Unicamp.

\section{Sobre o autor}

Possui graduação em Física - Bacharelado pela Universidade Federal de Santa Catarina (2007) e graduação em Música - Licenciatura pela Universidade do Estado de Santa Catarina (2012). Atualmente é Professor convidado da Universidade do Estado de Santa Catarina e mestrando na Universidade de São Paulo.

Recebido em: 19/09/2016

Aprovado em: 04/04/2017 